\title{
What the developing cerebral cortex tells about the adult cortex (and vice versa)
}

S. Herculano-Houzel
and R. Lent
Departamento de Anatomia, Instituto de Ciências Biomédicas, Universidade Federal do Rio de Janeiro, Rio de Janeiro, RJ, Brasil
A group of outstanding neuroscientists was seen last December in a most unusual place: the Maracanã soccer stadium in Rio de Janeiro, Brazil. The occasion was not a field trip, though, but an outing guided by local graduate students during the Fourth International Course of the UNESCO Chair of Morphology and Developmental Biology (1), which took place at the Federal University of Rio de Janeiro from December 3-7, 2001.

When it comes to discussing the frontiers of a particular research theme, there is no meeting like a small meeting, with plenty of discussion time after each lecture. This was the case at the UNESCO Course, which gathered over 200 participants. The 16 lectures on the theme "What the developing cerebral cortex tells about the adult cortex (and vice versa)", each followed by at least $20 \mathrm{~min}$ of debate with the audience, made clear that neuroscientists in the 21 st century are faced with several new concepts to accept, as well as old concepts to reexamine. The seven articles published in this issue will give the reader an idea of what was discussed in the meeting.

\section{What the developing cerebral cortex tells about the adult cortex...}

"Where do we come from?" is a question that has kept mankind occupied for centuries. The same can be asked of the human brain, but fortunately with a better prospect of obtaining answers. Where do brain cells come from, particularly those that form the adult cerebral cor- tex? How do they get there, acquire their adult characteristics and establish appropriate connections with other cells?

Recent progress in brain development was the theme explored during the first half of the symposium. Derek van der Kooy (University of Toronto, Canada) opened the symposium addressing the issue of what happens to the early embryonic cells that create the cortex once their job is done, and argued against the continued presence of stem cells in the adult brain other than in the remnants of the embryonic germinal zone in the lateral ventricles (2). These stem cells give rise to progenitors that express neuronal markers as they proliferate on their way to the adult olfactory bulb, where they replenish the neuronal population, as reviewed by João Menezes (Federal University of Rio de Janeiro, Brazil) $(3,4)$.

How do apparently similar proliferating cells form the different brain regions, each with characteristic cytoarchitectonics, chemical markers and connection patterns? Gradients of several homeobox genes are expressed over the embryonic brain, and based on that evidence, Dennis O'Leary (Salk Institute, USA) proposed that sharp areal boundaries might arise from the combination of different gradients (5), much as has been shown to occur in the development of the Drosophila body plan (6).

Do the two neuronal types of the adult cerebral cortex, pyramidal neurons and interneurons, share the same embryonic ori- 
gin? John Rubenstein (University of California at San Francisco, USA) reviewed evidence from his laboratory that most neocortical interneurons are actually derived from the ganglionic eminences, the germinal zone of the basal ganglia, and not from the cortical ventricular zone $(7,8)$. In order to find their way to the developing cerebral cortex, prospective interneurons may initially follow corticofugal axons in vivo, then migrate tangentially along the intermediate and marginal zones, and finally radially toward the inner cortical layers, according to evidence presented by John Parnavelas (University College London, UK) $(9,10)$. This novel mode of tangential-then-radial migration is further supported by unpublished data presented by Pasko Rakic (Yale University, USA) from two-photon microscopy of thick slabs of embryonic cerebral cortex in vitro. Additionally, neurotrophic factors might participate in guiding the migration of prospective cortical interneurons from the ganglionic eminences. Indeed, new data presented by Alan Pearlman (Washington University, USA) suggest that heterotopias caused by the application of NT-4 to the developing cortex consist of neurons generated in the ganglionic eminences.

Once neurons take up their final positions in the developing cerebral cortex, they start to extend processes that will constitute the adult brain circuitry. Katherine Kalil (University of Wisconsin, USA) reviewed evidence from her laboratory indicating that the extension of callosal axon collaterals can be influenced by the local environment (11). Before branching at the appropriate locations in the contralateral hemisphere, though, callosal axons must be guided across the midline, instead of diving down along the septum. Linda Richards (University of Maryland, USA) reviewed the role of midline glial and neuronal structures in guidance, and pointed out the involvement of the chemorepellent molecule Slit-2 in keeping callosal axons within the correct path $(12,13)$.

\section{... and vice versa}

While development answers questions concerning the origins of the adult brain, the layout of the adult cerebral cortex also gives clues about development. For instance, evidence presented by Jean-Christophe Houzel (Federal University of Rio de Janeiro, Brazil) shows that heterotopic callosal connections are common in visual areas, calling for a reevaluation of the notion that development leads to formation and selective survival solely of links between precisely matching points of the cerebral cortices $(14,15)$. Along the same lines, Miguel Nicolelis (Duke University, USA) reviewed data that indicate that receptive fields in the adult rat somatosensory cortex exhibit dynamic spatial properties, which can be shaped by early sensory experience, that are much less specific than previously thought. Additionally, these dynamic characteristics might provide a potential for immediate plastic reorganization of the adult cerebral cortex after peripheral injury, an issue reviewed by Ricardo Gattass (Federal University of Rio de Janeiro, Brazil) who discussed retinal lesion-induced plasticity of the blob system in the visual cortex of adult monkeys.

Adult plasticity is a relatively recent concept, and may be considered to represent a normal, previously underestimated capability of the adult brain. Indeed, recent evidence presented by Jeffrey Macklis (Harvard University, USA) suggests that re-activation of developmental mechanisms can occur - at least in special circumstances, when endogenous precursors can yield differentiated neurons that replenish lesioned areas (16).

\section{What the developing and adult cerebral cortex tell about evolution}

Any evolutionary theory concerning the origins of the mammalian brain must account for the acquisition of the six-layered, inside-out-generated neocortex, as pointed 
out by Francisco Aboitiz (University of Chile) (17). This would have required not only the evolution of radial organization of the cortex, but also a change from the reptilian, scattered pattern of reelin expression to the mammalian, marginal zone-restricted pattern, as argued by Andre Goffinet (University of Louvain, Belgium) (18).

Another striking feature of evolution of the mammalian neocortex, as proposed by Marcello Rosa (Monash University, Australia) (19), is cortical expansion through the addition of new areas. This is to say that cortical growth in evolution is not isometric: large brains cannot be considered to be magnified versions of smaller brains.

Invited by the organizing committee to use the final lecture to comment on what lessons development can teach about the adult brain, Pasko Rakic recalled the words of biologist Lewis Wolpert, who considers the first nine months to be the most important of human life, and concluded by quoting
Sigmund Freud, who wrote, albeit of a different body organ: "Anatomy is destiny".

The closing ceremony proceeded with the signature of an agreement between UNESCO and FAPERJ, the state science foundation, to implement an international laboratory in the Department of Anatomy, UFRJ, and provide travel grants that will facilitate scientific exchange with laboratories abroad. Launched in 1998, the UNESCO Chair of Morphology and Developmental Biology organizes each year a thematic course that brings to Brazil a set of international scientists, many students from different countries and a majority of Brazilian graduate students of various states. Presided by Professor Nicole Le Douarin (College de France), the Chair has organized courses on Experimental Models for Cellular and Molecular Embryology (1998 and 1999) and Stem Cells (2000). The courses have attracted a growing number of students each year, from 70 in 1998 to 260 in 2001.

\section{References}

1. Complete Program of the Fourth International Course of the UNESCO Chair of Morphology and Developmental Biology (2001). Federal University of Rio de Janeiro, Rio de Janeiro, RJ, Brazil. http:// www.unescortex.anato.icb.ufrj.br.

2. Seaberg RM \& van der Kooy D (2002). Adult rodent neurogenic regions: the ventricular subependyma contains neural stem cells, but the dentate gyrus contains restricted progenitors. Journal of Neuroscience, 22: 1784-1793.

3. Menezes JR, Froes MM, Moura Neto V \& Lent R (2000). Gap junction-mediated coupling in the postnatal anterior subventricular zone. Developmental Neuroscience, 22: 34-43.

4. Menezes JRL, Marins M, Alves JAJ, Fróes MM \& Hedin-Pereira C (2002). Cell migration in the postnatal subventricular zone. Brazilian Journal of Medical and Biological Research, 35: 1411-1421.

5. O'Leary DD \& Nakagawa Y (2002). Patterning centers, regulatory genes and extrinsic mechanisms controlling arealization of the neocortex. Current Opinion in
Neurobiology, 12: 14-25.

6. Lawrence PA (1992). The Making of a Fly: The Genetics of Animal Design. Blackwell Science, New York, NY, USA.

7. Anderson S, Eisenstat DD, Shi L \& Rubenstein JL (1997). Interneuron migration from basal forebrain to neocortex: dependence on Dlx genes. Science, 278: 474-476.

8. Anderson S, Mione M, Yun K \& Rubenstein JL (1999). Differential origins of neocortical projection and local circuit neurons: role of Dlx genes in neocortical interneuronogenesis. Cerebral Cortex, 9: 646-654

9. Denaxa M, Chan CH, Schachner M, Parnavelas JG \& Karagogeos D (2001). The adhesion molecule TAG-1 mediates the migration of cortical interneurons from the ganglionic eminence along the corticofugal fiber system. Development, 128: 4635-4644.

10. Parnavelas JG (2002). The origin of cortical neurons. Brazilian Journal of Medical and Biological Research, 35: 1423-1429.

11. Szebenyi G, Callaway JL, Dent EW \& Kalil
K (1998). Interstitial branches develop from active regions of the axon demarcated by the primary growth cone during pausing behaviors. Journal of Neuroscience, 18: 7930-7940.

12. Shu T \& Richards LJ (2001). Cortical axon guidance by the glial wedge during the development of the corpus callosum. Journal of Neuroscience, 21: 2749-2758.

13. Richards LJ (2002). Axonal pathfinding mechanisms at the cortical midline and in the development of the corpus callosum. Brazilian Journal of Medical and Biological Research, 35: 1431-1439.

14. Houzel JC \& Milleret C (1999). Visual inter-hemispheric processing: constraints and potentialities set by axonal morphology. Journal of Physiology, 93: 271-284.

15. Houzel J-C, Carvalho ML \& Lent R (2002). Interhemispheric connections between primary visual areas: beyond the midline rule. Brazilian Journal of Medical and Biological Research, 35: 1441-1453.

16. Fricker-Gates RA, Shin JJ, Tai CC, Catapano LA \& Macklis JD (2002). Late-stage immature neocortical neurons reconstruct 
interhemispheric connections and form synaptic contacts with increased efficiency in adult mouse cortex undergoing targeted neurodegeneration. Journal of Neuroscience, 22: 4045-4056.

17. Aboitiz F, Montiel J \& López J (2002). Critical steps in the early evolution of the isocortex. Insights from developmental biology. Brazilian Journal of Medical and Biological Research, 35: 1455-1472.

18. Tissir F, Lambert de Rouvroit C \& Goffinet AM (2002). The role of reelin in the development and evolution of the cerebral cortex. Brazilian Journal of Medical and Bio- logical Research, 35: 1473-1484.

19. Rosa MGP (2002). Visual maps in the adult primate cerebral cortex: some implications for brain development and evolution. Brazilian Journal of Medical and Biological Research, 35: 1485-1498. 